\title{
Sustained elevation of circulating GDF-15 and a dynamic imbalance in mediators of muscle homeostasis is associated with the development of acute muscle wasting following cardiac surgery
}

Dr Susannah AA Bloch MSc MRCP ${ }^{1,2^{*}}$, Jen Y Lee MRes BSc ${ }^{1}$, Dr S John Wort MA(Oxon) PhD ${ }^{2,3}$,Prof Michael I Polkey PhD FRCP ${ }^{2 \#}$, Dr Paul R Kemp BSc D.Phil ${ }^{1{ }^{*}}$,Dr Mark JD Griffiths PhD MRCP ${ }^{2,3 \#}$

${ }^{1}$ Molecular Medicine, National Heart and Lung Institute, Imperial College, London, United Kingdom

${ }^{2}$ Royal Brompton \& Harefield NHS Foundation Trust, NIHR Respiratory Biomedical Research Unit, London, United Kingdom

${ }^{3}$ Unit of Critical Care, National Heart and Lung Institute, Imperial College London, United Kingdom

\# Joint senior authorship - MG, PK and MIP, were all equally involved in this project and have equally contributed to this manuscript.

"Corresponding authors email: p.kemp@imperial.ac.uk, susannah.bloch@doctors.org.uk

This work was carried out in the departments of Molecular Medicine and Critical Care at the National Heart and Lung Institute, Imperial College London, United Kingdom.

The work was funded by the Medical Research Council, UK. 


\section{Abstract}

Objectives: Acute muscle wasting in the critically ill is common, and causes significant morbidity. In a novel human model of acute muscle wasting following cardiac surgery, known or potential circulating modulators of muscle mass: insulin-like growth factor-1 (IGF-1), myostatin and growth and differentiation factor-15 (GDF-15), were measured over a week. It was hypothesised that patients who developed acute muscle wasting would show distinct patterns of change in these mediators.

Design: A prospective longitudinal observational study of high-risk elective cardiac surgical patients identifying, by ultrasound, those developing muscle wasting.

Setting: Tertiary cardiothoracic referral centre: Royal Brompton Hospital, London, UK.

Patients: 42 patients undergoing elective high-risk cardiothoracic surgery.

Interventions: Circulating IGF-1, myostatin and GDF-15 were assayed pre-operatively and over the first week post-operatively. The ability of GDF-15 to cause muscle wasting in vitro was determined in C2C12 myotubes.

Measurements and main results: 23 of 42 patients (55\%) developed quadriceps atrophy. There was an acute decrease in IGF-1 and unexpectedly myostatin, known mediators of muscle hypertrophy and atrophy, respectively. By contrast, plasma GDF-15 concentrations increased in all patients. This increase in GDF-15 was sustained at day 7 in those who developed muscle wasting (day 7 compared with baseline, $p<0.01$ ), but recovered in the non-wasting group ( $>0.05)$. IGF-1 did not recover in those who developed muscle wasting (day 7 compared with baseline, $p<0.01$ ) but did in the nonwasting group ( $p>0.05$ ). Finally, we demonstrated that GDF-15 caused atrophy of myotubes in vitro.

Conclusion: These data support the hypothesis that acute muscle loss occurs as a result of an imbalance between drivers of muscle atrophy and hypertrophy. GDF-15 is a potential novel factor associated with muscle atrophy, which may become a therapeutic target in patients with Intensive care unit acquired paresis and other forms of acute muscle wasting.

Abstract word count: 292

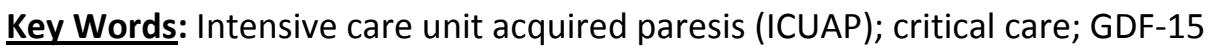




\section{Introduction}

Acute muscle loss in critically ill patients causes weakness ranging from mild loss of strength and muscle wasting to profound muscle weakness. Severe weakness in this context is known as intensive care unit acquired paresis (ICUAP), which is associated with significant mortality and morbidity [1]. Although it is a common problem, affecting at least $25 \%$ of patients admitted to critical care $[2,3]$, our understanding of the underlying pathological mechanisms is limited. Sepsis, systemic inflammatory response syndrome, immobility and hyperglycaemia are all thought to be major aetiological risk factors for the development of ICUAP [1, 4-7]. However, elucidation of the molecular mechanisms involved in human cases is difficult and evidence has often been contradictory. In part we believe this is because data is often obtained on ICU from heterogenous cohorts with a range of reasons for ICU admission and varying lengths of stay.

As in other disease processes muscle mass in critically ill patients is determined by the balance between dynamic processes mediating muscle breakdown (atrophy, apoptosis and autophagy) and synthesis (protein synthesis and satellite cell recruitment). Myostatin, a member of the TGF- $\beta$ superfamily, is a well recognised negative regulator of muscle mass [8], which has been implicated in the development of ICUAP. Elevation of both myostatin mRNA and protein was observed in the muscle of critically ill patients [9] and increased circulating levels of myostatin were observed in patients with muscle wasting associated with chronic obstructive pulmonary disease (COPD) [10], cardiac [11] and liver failure [12]. Other members of the TGF- $\beta$ family also regulate muscle phenotype. Growth and differentiation factor-15 (GDF-15) is a member of this family that under normal conditions is not expressed highly in most tissues [13]. However, expression is increased in response to oxidative stress, hypoxia, inflammation and tissue damage in liver, brain, lung and vascular tissue $[13,14]$. These factors are all thought to be important in the development of ICUAP [7]. GDF-15 is increasingly implicated in several disease processes including cardiovascular disease [14], multiple cancers [15-17], pulmonary artery hypertension [18] and importantly cachexia [19]. Furthermore in a mouse model of cardiac hypertrophy GDF-15 transgenic mice were resistant to cardiac hypertrophy and exposure to circulating GDF-15 limited cardiac myocyte hypertrophy [20].

Insulin like growth factor-1 (IGF-1) drives many hypertrophy pathways. Suppression of IGF-1 was observed in various animal models of sepsis and immobility [7] and in patients with severe ICUAP [21]. Although both increased myostatin and decreased IGF-1 have been implicated in the development of ICUAP, the relative pattern of change in the circulating levels of these mediators during the acute development of muscle wasting has not been established. Therefore, to identify potential circulating factors driving acute muscle wasting, we studied a homogenous cohort of 
patients undergoing high risk elective cardiothoracic surgery who were at risk of prolonged critical care admission and consequent muscle wasting. We hypothesised that the acute insult of surgery would result in an acute rise in the known circulating drivers of muscle breakdown (myostatin) and suppression of those promoting muscle hypertrophy (IGF-1) and that the dynamic pattern of these changes would differ between those patients who developed muscle wasting and those who did not. Furthermore, although a direct effect of GDF-15 on skeletal muscle has not been reported previously, the observations discussed above led us to hypothesise that circulating GDF-15 would rise following the acute stress of cardiothoracic surgery and be associated with muscle wasting. We went on to test our hypothesis further, by exposing cultured myotubes to GDF-15 in vitro.

\section{Methods}

\section{Patient recruitment and study design}

Written consent was obtained from all those involved in this prospective observational study (local research ethics committee approval 10/H0504/9). Adults undergoing elective cardiac surgery at the Royal Brompton Hospital were screened for inclusion in the study. The principle inclusion criteria was a high risk elective procedure requiring post operative admission to adult critical care, defined by the surgical team and by the patients' EuroSCORE [22-24]. Exclusion criteria included preexisting muscle or neuromuscular disease, malignancy or contraindication to serial blood sampling. Patients were only included if they were stable preoperatively and not suffering from acute illness or requiring emergency surgery. Muscle mass was assessed by measuring the cross-sectional area of the right rectus femoris muscle by ultrasound (see below) preoperatively and at day 7 of admission or at discharge from hospital if earlier than day 7. We obtained blood for analysis pre-operatively ('baseline') and repeat samples were taken on the $1^{\text {st }}$ and $2^{\text {nd }}$ postoperative days and at day 7 or at discharge if earlier; these latter two time points were considered identical for the purposes of analysis: only 4 patients ( 3 in the non-wasting patient group and 1 in the wasting group) were in fact discharged earlier than day 7.

\section{Measurement of ultrasound cross-sectional area of the rectus femoris.}

Ultrasound cross-sectional area of the rectus femoris (US $\mathrm{RF}_{\mathrm{csa}}$ ) was measured using a previously described technique $[25,26]$. B-mode US imaging with a $10 \mathrm{MHz} 12 \mathrm{~L}-\mathrm{RS}$ probe was used 
(Logiq E, GE Healthcare, UK). The patient was positioned lying supine on the bed with their legs flat with leg muscles relaxed. The anterior superior iliac spine (ASIS) and the point $60 \%$ of the distance from the ASIS to the superior border of the patella were identified. The US probe was positioned perpendicular to the axis of the leg. Where the entire $\mathrm{RF}_{\text {csa }}$ could not be visualised in a single US image a point $66 \%$ or $80 \%$ of the distance between the ASIS and patella was used. The same point was used for follow-up measurements for each patient. Three separate consecutive images were taken and the $\mathrm{RF}_{\mathrm{csa}}$ estimated using Image-J software (National Institutes of Health, USA). The average of these three measurements was used. Inadequate ultrasound images were defined as those where the edges of the RF muscle could not be defined well enough to calculate the $\mathrm{RF}_{\text {csa. }}$. This occurred where the patient was very oedematous and in these cases the patient data were excluded $(n=3)$.

\section{Patient classification; definition of quadriceps wasting}

Patients were classified as those who developed muscle wasting and those who did not based on the coefficient of variation (CV) of repeated measurements. To determine CV, the first 10 studies were repeated at 2 separate occasions on the same day. These measurements were then plotted on a Bland-Altman plot (Figure 1, supplemental digital content). This analysis determined that change in muscle loss of greater than $9.24 \%$ represented a significant change above the variation expected from repeated measures. Therefore those with greater than $9.24 \%$ muscle loss were categorised as having muscle wasting.

\section{Blood sample handling}

Plasma was separated from blood collected into EDTA sample tubes centrifuged at $1,500 \mathrm{~g}$ (3500 rpm) for 10 minutes, within 2 hours of collection. Samples were stored at $-80^{\circ} \mathrm{C}$ until they were processed.

\section{Sample analysis}

Plasma levels of myostatin (Immundiagnostik, Bensheim, Germany) and GDF-15 (R\&D systems, Abingdon, UK) and IGF-1 (Mediagnost, Reutlingen, Germany), were all quantified using commercially available ELISA kits. Results were analysed as per the manufactures guidelines. 
C2C12 myoblasts $\left(1 \times 10^{5}\right.$ per well) were seeded in a 6 well plate in growth medium (Dulbecco's modified eagle medium (DMEM) (Invitrogen, Paisley, UK) supplemented with $10 \%$ fetal calf serum (GE Heatlthcare, Little Chalfont, UK). The following day the cells were transfected with lipofectamine (Invitrogen) as previously described [27] with pCAGGS-GFP (0.5ug). The cells were allowed to differentiate, forming myotubes, in differentiation medium, (DMEM supplemented with $2 \%$ horse serum (GE Healthcare), for 7 days. On the 8th day of differentiation the cells were treated with fresh differentiation medium containing either the control vehicle (0.1\% BSA with 20mM HCL) or 50ng/ml GDF-15 (R\&D Systems) and cultured for a further 2 or 4 days.

Fluorescence images were taken 48 and 96 hours after treatment. Myotubes were identified in randomly selected fields. The width of each myotube was measured by determining the shortest distance across the cell at 5 randomly selected points along the length of the tube excluding branching regions of the cell, using Image J software. The experiment was repeated twice and each repeat showed a similar pattern: 43 control and 52 GDF-15 treated myotubes were measured in the first experiment and 25 control and 19 GDF-15 treated in the second at 48 hours. At 96 hours 47 control and 46 GDF-15 treated myotubes were measured in the first experiment and 24 control and 27 GDF-15 treated in the second. The data from the two experiments were combined for each time point.

\section{Data and Statistical analysis}

Data are quoted as mean +/- standard deviation (SD) unless otherwise stated. Raw Myostatin, GDF-15 and IGF-1 levels were non-parametrically distributed and so the median with interquartile ranges were used to describe the data. Repeated measures Friedman's test with Dunn's correction for comparison of all time points to the pre-operative baseline was used for within group analysis. GDF-15 levels were also analysed using regression with robust variances to determine the 'treatment' effect this is reported as the ratio of the geometric mean between wasting and nonwasting patients. Student's t-tests (for normally distributed data) or Mann-Whitney tests were used where appropriate for between group analyses. Statistical analysis and figure construction was carried out using Graphpad PRISM 5 (GraphPad Software, California, USA). 


\section{$\underline{\text { Results }}$}

\section{$\underline{\text { Patients and data collection }}$}

50 patients meeting the inclusion criteria were approached: 5 declined consent and in 3 patients we were unable to achieve good quality US $\mathrm{RF}_{\text {csa }}$ images. Of the remaining 42,23 developed muscle wasting following surgery (Figure 1). Baseline demographic data, patient co-morbidities and critical care data are shown in table 1 . The different surgical procedures undergone are shown in table 1 of the supplemental digital content. The non-wasting and wasting patient groups were well matched for age, sex, BMI and EuroSCORE (table 1). Total Bypass time for both groups is also shown. Not all patients underwent bypass as one patient in the non-wasting group underwent an off-pump coronary artery bypass procedure and 3 underwent transcutaneous aortic valve insertion; in the wasting group 2 patients had off-pump procedures. Importantly these patients behaved in the same way as the rest of their group and the circulating plasma levels for the mediators measured are within the range of the rest of the group. Length of stay in ICU was short with a median stay of only 1 day for the non-wasting patients and 2 for those who developed muscle wasting ( $p=0.62$ MannWhitney). Length of stay in hospital was also similar in the two groups (median 8 for non-wasting and 9 for wasting patients, $p=0.44$ Mann-Whitney). Only one patient died, at 21 days postoperatively, in the wasting group; no patients died in the non-wasting group.

\section{Change in US RF $c s a$}

The mean change in US $\mathrm{RF}_{\text {csa }}$ from baseline over the week for the wasting group $(n=23)$ was a loss of $24.6 \pm 13.7 \%$ (figure 1 ). The mean change in the non-wasting group $(n=19)$ was not significant $(1.3 \pm 5.9 \%)$.

\section{Myostatin}

Baseline plasma myostatin did not differ significantly between the groups $(p=0.1)$. Unexpectedly plasma myostatin concentration fell significantly in both groups following surgery. In both groups plasma myostatin concentration returned to baseline at day 7 (figure 2). 
Baseline plasma GDF-15 also did not differ significantly between the groups ( $p=0.52)$. In contrast to myostatin, GDF-15 levels increased dramatically after surgery ( $p<0.001$ for both groups). In the non-wasting patients the increase in GDF-15 returned to baseline by day 7 ( $p>0.05)$, however in the wasting group the level remained significantly elevated ( $p<0.01$ : figure 3 ). The ratio of the geometric mean of GDF-15 for non-wasting subjects to wasting subjects was $1.17(0.97,1.41)$ suggesting that the geometric mean for the non-wasting subjects was on the average higher than that for the wasting subjects over the period, although the ratio failed to achieve statistical significance $p=0.10$ This together suggests a higher relative exposure to circulating GDF-15 in the wasting patients in comparison those in whom muscle wasting did not develop.

$\underline{I G F-1}$

Baseline plasma IGF-1 did not differ significantly between the groups $(p=0.22)$. The pattern of change in IGF-1 levels after surgery was the same in both groups, the IGF-1 plasma concentration fell significantly at days 1 and 2 after surgery in both groups ( $p<0.001$ for both). In the non-wasting group the IGF-1 concentration returned to baseline by day 7 ( $p>0.05)$. However, in wasting patients it remained significantly reduced at day 7 ( $p<0.01$ : figure 4$)$.

\section{Effect of GDF-15 on myotube diameter}

In order to test the hypothesis that GDF-15 can induce skeletal muscle wasting, we exposed cultured $\mathrm{C} 2 \mathrm{C} 12$ differentiated myotubes to GDF-15 $(50 \mathrm{ng} / \mathrm{ml})$ for 48 and 96 hours. Treatment with GDF-15 induced significant wasting of these fibres when compared to control (figure 5). The median (interquartile ranges) control myotube diameter at $48 \mathrm{hrs}$ was $26.4(18.2,32.3) \mu \mathrm{m}$ versus 19.9 (17.0 ,27.5) $\mu \mathrm{m},(p=0.011$ Mann-Whitney: figure 5$)$ for the GDF-15 treated myotubes. This equates to a $25 \%$ reduction of the median diameter following GDF-15 treatment. At 96 hours median control myotube diameter was $24.9(20.1,33.1) \mu \mathrm{m}$ and $21.2(17.1,26.1) \mu \mathrm{m}$ for GDF-15 treated myotubes ( $15 \%$ reduction of the median, $p=0.003$ Mann-Whitney). 


\section{Discussion}

Our data confirm that measurable muscle loss is common in patients undergoing planned high-risk cardiac surgery which was uncomplicated and followed by a short ICU stay. Secondly, a potential novel mediator of muscle wasting, GDF-15 showed a more sustained rise in those patients who developed muscle wasting than in those who do not. Thirdly, in a separate experiment we confirmed in vitro that GDF-15 can induce myotube atrophy. We observed, as expected, a reduction in circulating IGF-1 levels that recovered to baseline by day 7 in non-wasting patients, but not in those who developed muscle wasting (figure 4). However, circulating myostatin behaved in the opposite way to that expected and was suppressed in the acute phase. Together these data imply that in patients who develop muscle wasting, there is a sustained imbalance in the factors that determine muscle homeostasis in a direction promoting muscle wasting. In all our patients this balance is upset by the insult of cardiac surgery. In those who do not develop muscle wasting the balance is restored as levels of IGF-1 and GDF-15 return to pre-surgery levels by day 7. Conversely in those who develop muscle wasting IGF-1 remains reduced and GDF-15 remains increased at day 7 indicating that the balance of these two factors has not been restored. This lack of restoration of the normal regulation of these synthetic and atrophic factors may contribute to muscle wasting in this group. We suspect that GDF-15 excess is a hitherto unknown mechanism, which contributes in some circumstances to skeletal muscle atrophy in humans.

Myostatin is a well recognised negative modulator of muscle mass, [8] so we expected circulating levels to be elevated in patients who developed quadriceps atrophy. However our data suggest that GDF-15 rather than myostatin is more likely to be a driver of acute muscle atrophy in this patient cohort. Circulating myostatin levels were, contrary to what was expected $[7,8]$, suppressed in the acute phase and recovered in both wasted and non-wasting patients (Figure 2). However circulating GDF-15 rose acutely and also remained elevated for longer in the wasting group with GDF-15 only returning to baseline by day 7 in those who did not develop muscle wasting (figure $3)$.

With respect to IGF-1, these clinical data are consistent with the current understanding of muscle wasting. IGF-1 in muscle was suppressed in human studies of sepsis [28, 29], immobility [30], following surgery [31] and in critical illness [32]. Reduced plasma IGF-1 levels have also been observed in acute critical illness [32], and have been associated with poor clinical outcome [33] and the development of severe ICUAP [21]. However, the data concerning myostatin are less conclusive. 
Despite a variety of muscle wasting conditions being associated with elevated levels of both muscle and plasma myostatin $[8,10,11,34-36]$, evidence from the acute phase of critical illness has been contradictory. For example, an increase in myostatin mRNA and protein from skeletal muscle of patients in the acute phase of critical illness has been reported [9], although this observation was not repeated in a more diverse population [32]. A recently published large study of 208 muscle biopsies in ICU patients with prolonged stays on ICU showed decreased myostatin mRNA in the rectus abdominis (taken immediately after death), but no change in vastus lateralis levels when compared to controls [37]. Data from various animal models also suggest that acute muscle wasting secondary to sepsis or inflammatory insult may not be driven by myostatin [38]. In fact following cecal ligation and puncture a significant reduction in myostatin mRNA both in muscle and circulating plasma myostatin was seen in rats acutely [39], an observation consistent with our data. Gene microarray analysis in a rat model, which included immobility, ventilation and neuromuscular blockade but not sepsis, showed acute elevation of myostatin mRNA, followed by suppression over the next week [40].

Our clinical data show the association of a more prolonged exposure to GDF-15 with the development of muscle wasting following cardiac surgery, therefore is it possible that this association may represent a novel mechanism for acute muscle wasting. GDF-15 was first described as macrophage inhibitory cytokine -1 (MIC-1) and has hallmark characteristics of the TGF- $\beta$ family of proteins [41]. It is secreted as a pro-peptide and cleaved to form a dimeric mature protein of 224 amino acids [14]. GDF-15 expression increased in response to stress, hypoxia and inflammation in vitro $[14,17]$ and in a variety of animal and human chronic disease settings $[13,17,18]$. All the patients in this study underwent the significant acute inflammatory insult of cardiac surgery and as expected circulating GDF-15 rose acutely in all patients.

To our knowledge, a direct effect of GDF-15 on skeletal muscle has not previously been demonstrated. GDF-15 induced significant fibre atrophy of cultured C2C12 myotubes. This result is consistent with data from cardiac and cancer cell lines, and models in which GDF-15 limited hypertrophy and promoted apoptosis $[16,20]$. In relation to cardiac hypertrophy, limitation is clinically beneficial. Mice deficient in GDF-15 show both increased hypertrophy and loss of cardiac function in response to pressure overload when compared to wild type mice. [20]. Beneficial effects of GDF-15 in cardiac tissue also include the protection of the myocardium from infiltration of polymorphonuclear leukocytes and protection against myocardial rupture following infarction [42]. 
However even within cardiac tissue GDF-15 is also linked to pathological effects and its role is likely to be bidirectional depending on the situation and environment [14]. A similar situation is seen in cancer cells with some evidence pointing towards a protective role for example by promoting apoptosis in prostate cancer cells $[43,44]$ and some suggesting that GDF-15 may play a role in carcinogenesis, for example by enhancing metastatic potential and angiogenesis [13]. It is possible that in muscle tissue a similar situation exists such that the role of GDF-15 may depend on the molecular environment. However our findings of an association between GDF-15 and acute muscle wasting following the physiological stress of cardiac surgery are consistent with the understanding that GDF-15 is released under situations of physiological stress $[13,14]$. The ability of GDF-15 to cause muscle wasting in cultured myotubes is consistent with the antihypertrophy/ pro-apoptosis role described above at least under some conditions. Also cancer related cachexia in mice resulting from excess GDF-15 expression from transplanted prostate cancer cells can be reversed with GDF-15 antibodies [19]. It was postulated that this was due to a central anti-anorexic effect and reduced food intake was reversed. However our data suggest that it is possible that GDF-15 also has a direct effect on skeletal muscle resulting in reduced muscle bulk and lean body mass.

Critique of method.

A weakness of our data is that we are unable to demonstrate a difference between the two groups on the raw values of circulating factor's concentrations alone. This may be due to the relatively small number of patients in each group and the wide range of baseline values. Alternatively, despite the high risk nature of the cardiothoracic surgery that our patients underwent, the overall clinical outcome was very good, in that ICU stay was short with a low mortality. Moreover, although measurable, these patients can be considered to only have mild muscle wasting with clinically insignificant weakness and therefore differences between the two groups will be harder to detect. Nevertheless, the validity of our approach is supported by the observation that IGF-1 decreased acutely in all patients, and remained suppressed in those who developed muscle wasting, consistent with prior observations [21, 32]. A larger prospective study involving more patients and patients with clinically obvious ICUAP would be desirable as a next step to confirm our findings.

It is well established that the use of bypass per se may influence circulating levels of inflammatory molecules [45]. However we do not believe this explains the current data because bypass time was not different in patients who developed wasting and those who did not (Table 1). In addition 4 patients in the non-wasting group and 2 in the wasting group did not undergo bypass 
and these patients had circulating plasma levels for the mediators measured of the same order of magnitude as the rest of the group.

A perfect human model of ICUAP does not exist. However, we believe our experimental paradigm is of interest owing to its prospective nature and the relative homogeneity of the patient cohort and the insult. By contrast, elucidating mechanisms of ICUAP by studying cases is also problematic because ICUAP is a heterogeneous disorder that occurs in a very mixed cohort of patients and the time course of the syndrome is difficult to define. Our model can be criticised for the fact that patients only develop subclinical muscle weakness and therefore it may be difficult to extrapolate findings to true ICUAP. It is also important to acknowledge that although these patients have all undergone significant physiological insult the cardiac surgical model may not be generally applicable to ICU patients - in whom for example sepsis and prolonged stays on critical care are common. However the strengths of the model are that by studying our patients' blood profile from baseline, we are able to demonstrate prospectively the dynamic pattern of change of circulating drivers of muscle metabolism. Furthermore by identifying prospectively a specific cohort of patients with similar clinical experiences we are able to control for many variables and potentially identify specific factors in the pathophysiology of acute muscle wasting in the critically ill.

In conclusion, we have shown that even elective high risk cardiac surgery with a good clinical outcome is commonly associated with measurable loss of quadriceps muscle mass; and our data supports the hypothesis that this muscle loss occurs as a result of a dynamic imbalance between drivers of muscle atrophy and hypertrophy. Furthermore we speculate that GDF-15 may be a clinically relevant cause of skeletal muscle wasting in humans; if so GDF-15 antagonism may prove a useful future therapeutic approach. 


\section{Acknowledgements}

Susannah Bloch and Jen Lee are funded by the Medical Research Council. The project was supported by the NIHR Respiratory Disease Biomedical Research Unit at the Royal Brompton and Harefield NHS Foundation Trust and Imperial College London, who part fund the salaries of MIP and MG. 


\section{References}

1. Latronico N, Bolton CF: Critical illness polyneuropathy and myopathy: a major cause of muscle weakness and paralysis. Lancet Neurol 2011, 10(10):931-941.

2. De Jonghe B, Sharshar T, Lefaucheur J, Authier F, Durand-Zaleski I, Boussarsar M, Cerf C, Renaud E, Mesrati F, Carlet J et al: Paresis acquired in the intensive care unit: a prospective multicenter study. JAMA 2002, 288(22):2859-2867.

3. Ali N, O'Brien JJ, Hoffmann S, Phillips G, Garland A, Finley J, Almoosa K, Hejal R, Wolf K, Lemeshow $\mathrm{S}$ et al: Acquired weakness, handgrip strength, and mortality in critically ill patients. Am J Respir Crit Care Med 2008, 178(3):261-268.

4. Stevens R, Dowdy D, Michaels R, Mendez-Tellez P, Pronovost P, Needham D: Neuromuscular dysfunction acquired in critical illness: a systematic review. Intensive Care Med 2007, 33(11):1876-1891.

5. Van den Berghe G, Schoonheydt K, Becx P, Bruyninckx F, Wouters P: Insulin therapy protects the central and peripheral nervous system of intensive care patients. Neurology 2005, 64(8):1348-1353.

6. Hermans $G$, Wilmer A, Meersseman W, Milants I, Wouters $P$, Bobbaers H, Bruyninckx F, Van den Berghe G: Impact of intensive insulin therapy on neuromuscular complications and ventilator dependency in the medical intensive care unit. Am J Respir Crit Care Med 2007, 175(5):480-489.

7. Bloch S, Polkey MI, Griffiths M, Kemp P: Molecular mechanisms of intensive care unitacquired weakness. Eur Respir J 2012, 39(4):1000-1011.

8. Elliott B, Renshaw D, Getting S, Mackenzie R: The central role of myostatin in skeletal muscle and whole body homeostasis. Acta Physiol (Oxf) 2012, 205(3):324-340.

9. Constantin D, McCullough J, Mahajan RP, Greenhaff PL: Novel events in the molecular regulation of muscle mass in critically ill patients. J Physiol 2011, 589(Pt 15):3883-3895.

10. Ju CR, Chen RC: Serum myostatin levels and skeletal muscle wasting in chronic obstructive pulmonary disease. Respir Med 2012, 106(1):102-108.

11. Gruson D, Ahn SA, Ketelslegers JM, Rousseau MF: Increased plasma myostatin in heart failure. Eur J Heart Fail 2011, 13(7):734-736.

12. Garcia PS, Cabbabe A, Kambadur R, Nicholas G, Csete M: Brief-reports: elevated myostatin levels in patients with liver disease: a potential contributor to skeletal muscle wasting. Anesth Analg 2010, 111(3):707-709.

13. Mimeault M, Batra SK: Divergent molecular mechanisms underlying the pleiotropic functions of macrophage inhibitory cytokine-1 in cancer. J Cell Physiol 2010, 224(3):626-635.

14. Xu X, Li Z, Gao W: Growth differentiation factor 15 in cardiovascular diseases: from bench to bedside. Biomarkers 2011, 16(6):466-475.

15. Corre J, Labat E, Espagnolle N, Hebraud B, Avet-Loiseau H, Roussel M, Huynh A, Gadelorge $M$, Cordelier P, Klein B et al: Bioactivity and Prognostic Significance of Growth Differentiation Factor GDF15 Secreted by Bone Marrow Mesenchymal Stem Cells in Multiple Myeloma. Cancer Res 2012, 72(6):1395-1406.

16. Schiegnitz E, Kammerer PW, Koch FP, Kruger M, Berres M, Al-Nawas B: GDF 15 as an antiapoptotic, diagnostic and prognostic marker in oral squamous cell carcinoma. Oral Oncol 2012, 48(7):608-614.

17. Vanhara P, Hampl A, Kozubik A, Soucek K: Growth/differentiation factor-15: prostate cancer suppressor or promoter? Prostate Cancer Prostatic Dis 2012 Epub date 2012/03/01.

18. Meadows CA, Risbano MG, Zhang L, Geraci MW, Tuder RM, Collier DH, Bull TM: Increased expression of growth differentiation factor-15 in systemic sclerosis-associated pulmonary arterial hypertension. Chest 2011, 139(5):994-1002.

19. Johnen $\mathrm{H}$, Lin $\mathrm{S}$, Kuffner $\mathrm{T}$, Brown DA, Tsai VW, Bauskin AR, Wu L, Pankhurst G, Jiang L, Junankar $S$ et al: Tumor-induced anorexia and weight loss are mediated by the TGF-beta superfamily cytokine MIC-1. Nat Med 2007, 13(11):1333-1340. 
20. Xu J, Kimball TR, Lorenz JN, Brown DA, Bauskin AR, Klevitsky R, Hewett TE, Breit SN, Molkentin JD: GDF15/MIC-1 functions as a protective and antihypertrophic factor released from the myocardium in association with SMAD protein activation. Circ Res 2006, 98(3):342350.

21. Sharshar T, Bastuji-Garin S, De Jonghe B, Stevens RD, Polito A, Maxime V, Rodriguez P, Cerf $\mathrm{C}$, Outin $\mathrm{H}$, Touraine $\mathrm{P}$ et al: Hormonal status and ICU-acquired paresis in critically ill patients. Intensive Care Med 2010, 36(8):1318-1326.

22. Nashef SA, Roques F, Michel P, Gauducheau E, Lemeshow S, Salamon R: European system for cardiac operative risk evaluation (EuroSCORE). Eur J Cardiothorac Surg 1999, 16(1):9-13.

23. Roques F, Nashef SA, Michel P, Gauducheau E, de Vincentiis C, Baudet E, Cortina J, David M, Faichney A, Gabrielle F et al: Risk factors and outcome in European cardiac surgery: analysis of the EuroSCORE multinational database of 19030 patients. Eur J Cardiothorac Surg 1999, 15(6):816-822; discussion 822-813.

24. Messaoudi N, De Cocker J, Stockman BA, Bossaert LL, Rodrigus IE: Is EuroSCORE useful in the prediction of extended intensive care unit stay after cardiac surgery? Eur J Cardiothorac Surg 2009, 36(1):35-39.

25. Seymour J, Ward K, Sidhu P, Puthucheary Z, Steier J, Jolley C, Rafferty G, Polkey M, Moxham $\mathrm{J}$ : Ultrasound measurement of rectus femoris cross-sectional area and the relationship with quadriceps strength in COPD. Thorax 2009, 64(5):418-423.

26. Shrikrishna D, Patel M, Tanner RJ, Seymour JM, Connolly BA, Puthucheary ZA, Walsh SL, Bloch SA, Sidhu PS, Hart N et al: Quadriceps wasting and physical inactivity in patients with COPD. Eur Respir J 2012.

27. Favot L, Hall SM, Haworth SG, Kemp PR: Cytoplasmic YY1 is associated with increased smooth muscle-specific gene expression: implications for neonatal pulmonary hypertension. Am J Pathol 2005, 167(6):1497-1509.

28. Lang $\mathrm{CH}$, Frost RA: Role of growth hormone, insulin-like growth factor-I, and insulin-like growth factor binding proteins in the catabolic response to injury and infection. Curr Opin Clin Nutr Metab Care 2002, 5(3):271-279.

29. Vesali RF, Cibicek N, Jakobsson T, Klaude M, Wernerman J, Rooyackers O: Protein metabolism in leg muscle following an endotoxin injection in healthy volunteers. Clin Sci (Lond) 2010, 118(6):421-427.

30. Hornberger TA, Hunter RB, Kandarian SC, Esser KA: Regulation of translation factors during hindlimb unloading and denervation of skeletal muscle in rats. Am J Physiol Cell Physiol 2001, 281(1):C179-187.

31. Petersson B, Wernerman J, Waller SO, von der Decken A, Vinnars E: Elective abdominal surgery depresses muscle protein synthesis and increases subjective fatigue: effects lasting more than 30 days. Br J Surg 1990, 77(7):796-800.

32. Jespersen JG, Nedergaard A, Reitelseder S, Mikkelsen UR, Dideriksen KJ, Agergaard J, Kreiner F, Pott FC, Schjerling P, Kjaer M: Activated protein synthesis and suppressed protein breakdown signaling in skeletal muscle of critically ill patients. PLoS One 2011, 6(3):e18090.

33. Sharshar T, Bastuji-Garin S, Polito A, De Jonghe B, Stevens RD, Maxime V, Rodriguez P, Cerf $C$, Outin $\mathrm{H}$, Touraine $\mathrm{P}$ et al: Hormonal status in protracted critical illness and in-hospital mortality. Crit Care 2011, 15(1):R47.

34. Gonzalez-Cadavid NF, Taylor WE, Yarasheski K, Sinha-Hikim I, Ma K, Ezzat S, Shen R, Lalani R, Asa $\mathrm{S}$, Mamita $\mathrm{M}$ et al: Organization of the human myostatin gene and expression in healthy men and HIV-infected men with muscle wasting. Proc Natl Acad Sci U S A 1998, 95(25):14938-14943.

35. Han DS, Chen YM, Lin SY, Chang HH, Huang TM, Chi YC, Yang WS: Serum myostatin levels and grip strength in normal subjects and patients on maintenance haemodialysis. Clin Endocrinol (Oxf) 2011, 75(6):857-863.

36. Schuelke M, Wagner KR, Stolz LE, Hubner C, Riebel T, Komen W, Braun T, Tobin JF, Lee SJ: Myostatin mutation associated with gross muscle hypertrophy in a child. N Engl J Med 2004, 350(26):2682-2688. 
37. Derde S, Hermans G, Derese I, Guiza F, Hedstrom Y, Wouters PJ, Bruyninckx F, D'Hoore A, Larsson L, Van den Berghe $G$ et al: Muscle atrophy and preferential loss of myosin in prolonged critically ill patients. Crit Care Med 2012, 40(1):79-89.

38. Lang $\mathrm{CH}$, Silvis C, Nystrom G, Frost RA: Regulation of myostatin by glucocorticoids after thermal injury. FASEB J 2001, 15(10):1807-1809.

39. Smith IJ, Aversa Z, Alamdari N, Petkova V, Hasselgren PO: Sepsis downregulates myostatin mRNA levels without altering myostatin protein levels in skeletal muscle. J Cell Biochem 2010, 111(4):1059-1073.

40. Llano-Diez M, Gustafson AM, Olsson C, Goransson H, Larsson L: Muscle wasting and the temporal gene expression pattern in a novel rat intensive care unit model. BMC Genomics 2011, 12:602.

41. Bootcov MR, Bauskin AR, Valenzuela SM, Moore AG, Bansal M, He XY, Zhang HP, Donnellan $\mathrm{M}$, Mahler S, Pryor $\mathrm{K}$ et al: MIC-1, a novel macrophage inhibitory cytokine, is a divergent member of the TGF-beta superfamily. Proc Natl Acad Sci U S A 1997, 94(21):11514-11519.

42. Kempf T, Zarbock A, Widera C, Butz S, Stadtmann A, Rossaint J, Bolomini-Vittori M, KorfKlingebiel M, Napp LC, Hansen B et al: GDF-15 is an inhibitor of leukocyte integrin activation required for survival after myocardial infarction in mice. Nat Med 2011, 17(5):581-588.

43. Kim KS, Baek SJ, Flake GP, Loftin CD, Calvo BF, Eling TE: Expression and regulation of nonsteroidal anti-inflammatory drug-activated gene (NAG-1) in human and mouse tissue. Gastroenterology 2002, 122(5):1388-1398.

44. Liu T, Bauskin AR, Zaunders J, Brown DA, Pankhurst S, Russell PJ, Breit SN: Macrophage inhibitory cytokine 1 reduces cell adhesion and induces apoptosis in prostate cancer cells. Cancer Res 2003, 63(16):5034-5040.

45. Anselmi A, Abbate A, Girola F, Nasso G, Biondi-Zoccai GG, Possati G, Gaudino M: Myocardial ischemia, stunning, inflammation, and apoptosis during cardiac surgery: a review of evidence. Eur J Cardiothorac Surg 2004, 25(3):304-311. 
A



B



Figure 1: A: Change in rectus femoris US cross-sectional area (US $R_{\text {csa }}$ ) from pre-operative baseline to day 7 in high risk elective cardiac surgery patients who did not develop muscle wasting (nonwasting $n=19 p=0.14$ paired student's t test) and those who did develop muscle wasting $(>9.24 \%$ loss, wasting $n=23 p=<0.0001$ paired student's t test).

B: Change in US RF $\mathrm{Csa}_{\text {csa }}$ expressed as percentage change from baseline. Non-wasting patients change in US $\mathrm{RF}_{\text {csa }} 1.3 \% \pm 5.9$ and in the wasting group $24.6 \% \pm 13.7$ (mean \pm SD). 




Figure 2: Plasma Myostatin concentration ( $\mathrm{ng} / \mathrm{ml})$ in non-wasting $(\mathrm{n}=19)$ and wasting patients (those with $>9.24 \%$ muscle loss: $n=23$ ) pre-operatively (PO), on day 1 (D1), day 2 (D2) and on day 7 (D7). Data presented as box and whisker plots with median, interquartile ranges and $5-95 \%$ percentiles. * $\mathrm{p}<0.05,{ }^{* *} \mathrm{p}<0.01,{ }^{* * *} \mathrm{p}<0.001$, ns - not significant, repeated measures Freidman's test with Dunn's correction for comparison with pre-operative baseline. 


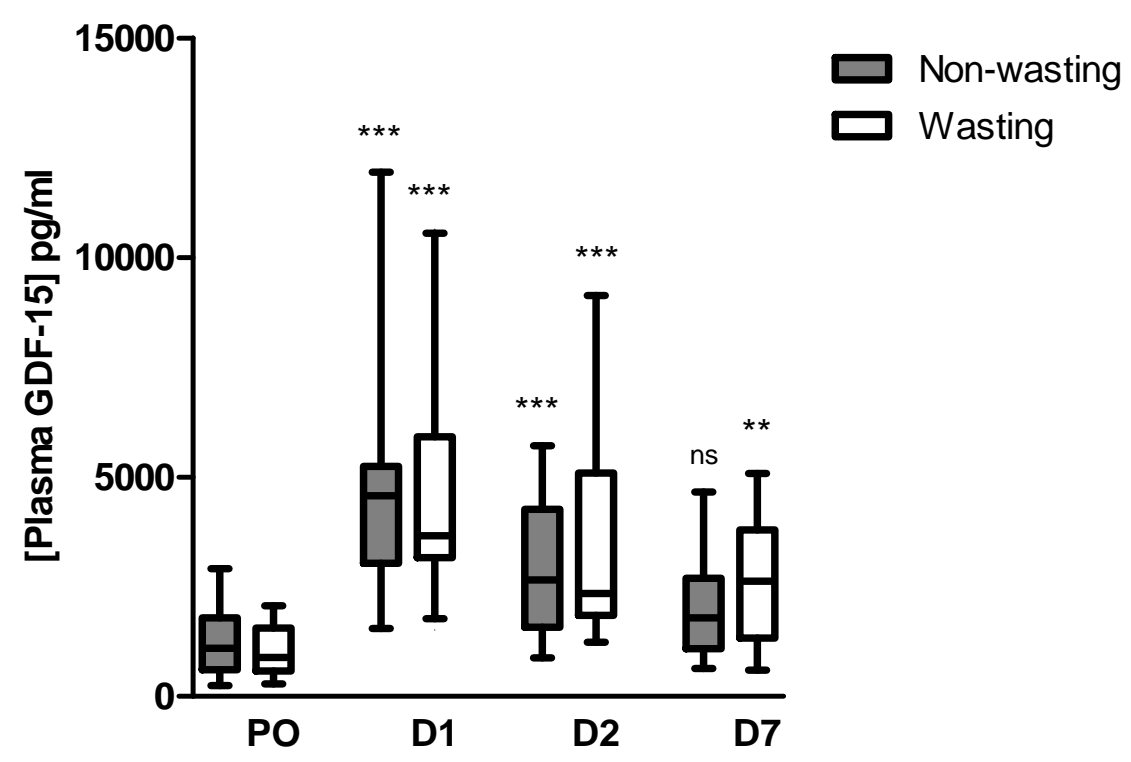

Figure 3: Plasma GDF-15 concentration $(\mathrm{pg} / \mathrm{ml})$ in non-wasting $(\mathrm{n}=19)$ and wasting patients (those with $>9.24 \%$ muscle loss: $n=23$ ) pre-operatively (PO), on day 1 (D1), day 2 (D2) and on day 7 (D7). Data presented as box and whisker plots with median, interquartile ranges and 5-95\% percentiles. * $\mathrm{p}<0.05, * * \mathrm{p}<0.01, * * * \mathrm{p}<0.001$, ns - not significant, repeated measures Friedman's with Dunn's correction for comparison with pre-operative baseline. 


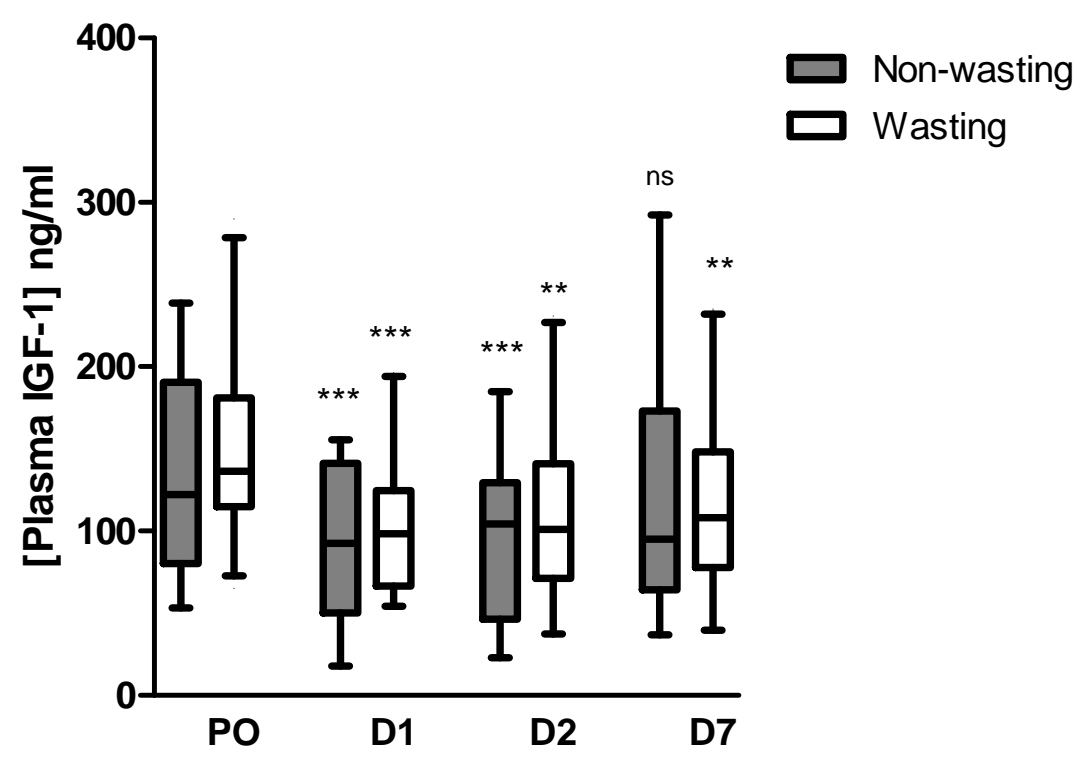

Figure 4: Plasma IGF-1 concentration $(\mathrm{ng} / \mathrm{ml})$ in non-wasting $(\mathrm{n}=19)$ and wasting patients (those with $>9.24 \%$ muscle loss: $n=23$ ) pre-operatively (PO), on day 1 (D1), day 2 (D2) and on day 7 (D7). Data presented as box and whisker plots with median, interquartile ranges and 5-95\% percentiles. ${ }^{*} \mathrm{p}<0.05,{ }^{* *} \mathrm{p}<0.01,{ }^{* * *} \mathrm{p}<0.001$, ns - not significant, repeated measures Freidman's test with Dunn's correction for comparison with pre-operative baseline. 

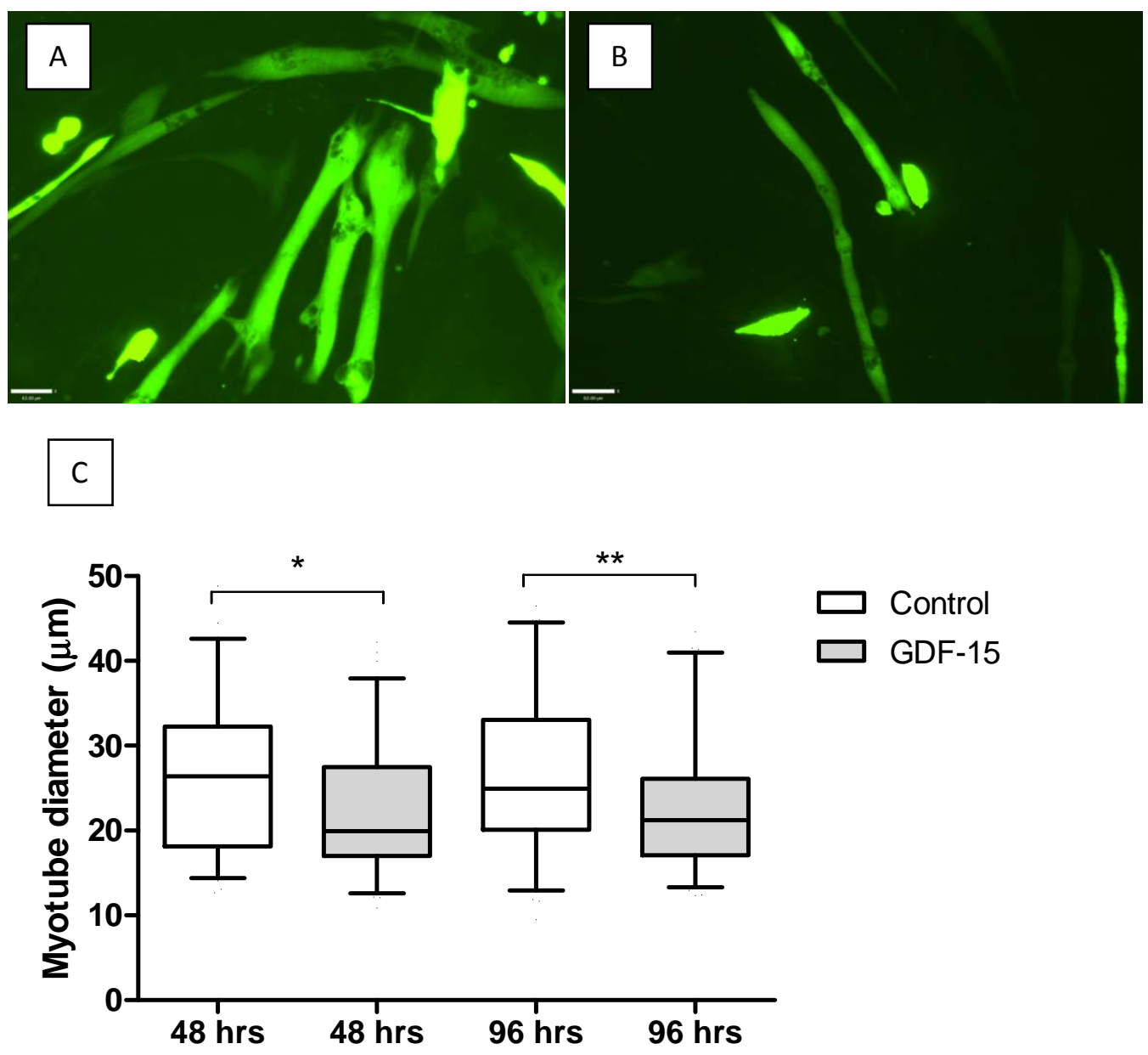

Figure 5. GFP transfected myotubes following treatment with control (A) or GDF-15 50ng/ml (B) for 48 hours on day 8 of differentiation (x10 magnification). (C): Box and Whisker plots show median, interquartile range and $5^{\text {th }}$ and $95^{\text {th }}$ centiles. Day 8 cultured myotubes were exposed to GDF-15 (50ng/ml) or vehicle control $(0.1 \%$ BSA with $20 \mathrm{mM} \mathrm{HCL})$ for 48 or 96 hours. Diameter of the myotubes was then calculated. Mean control myotube diameter was $26.3 \pm 9.0 \mu \mathrm{m}$ versus $22.3 \pm 7.5$ $\mu \mathrm{m}$ for the GDF-15 treated myotubes at 48 hours. This equates to a $15 \%$ reduction in diameter following GDF-15 treatment; $p=0.011$ (Mann-Whitney). At 96 hours mean control myotube diameter was $26.6 \pm 9 \mu \mathrm{m}$ and $22.7 \pm 8 \mu \mathrm{m}$ for GDF-15 treated myotubes (14\% reduction $\mathrm{p}=0.003$ MannWhitney) 


\begin{tabular}{|c|c|c|c|}
\hline & $\begin{array}{l}\text { Non-wasting patients } \\
(n=19)\end{array}$ & $\begin{array}{l}\text { Wasting patients } \\
(n=23)\end{array}$ & $\begin{array}{l}\text { P value } \\
\text { (T-test, } \\
\text { \#Mann-Whitney) }\end{array}$ \\
\hline \multicolumn{4}{|l|}{ Demographic data } \\
\hline Age (years) & $65.7 \pm 17.2$ & $62.0 \pm 16.2$ & 0.47 \\
\hline $\operatorname{Sex}(m / f)$ & $9 / 10$ & $12 / 11$ & \\
\hline $\mathrm{BMI}\left(\mathrm{kg} / \mathrm{m}^{2}\right)^{*}$ & $26.6 \pm 4.6$ & $24.7 \pm 4.1$ & 0.18 \\
\hline EuroSCORE & $5.3 \pm 1.8$ & $5.5 \pm 2.6$ & 0.76 \\
\hline Pre-op LVEF $\%^{+}$ & $60.8 \pm 15.0$ & $56.6 \pm 16.4$ & 0.41 \\
\hline $\begin{array}{l}\text { Pre-op Creatinine (umol/L) } \\
*\end{array}$ & $81.3 \pm 23.6$ & $77.3 \pm 17.1$ & 0.52 \\
\hline $\begin{array}{l}\text { Pre op Creatinine clearance } \\
(\mathrm{ml} / \mathrm{min})^{*}\end{array}$ & $84.7 \pm 36.1$ & $86.8 \pm 34.7$ & 0.66 \\
\hline \multicolumn{4}{|l|}{$\begin{array}{l}\text { Pre operative Co-morbidities } \\
\text { (n) }\end{array}$} \\
\hline Ischemic heart disease & 10 & 8 & \\
\hline Structural heart disease & 9 & 11 & \\
\hline Dysrhythmia & 2 & 3 & \\
\hline Systemic hypertension & 7 & 5 & \\
\hline Pulmonary hypertension & 1 & 2 & \\
\hline Hypercholesterolemia & 7 & 10 & \\
\hline Congenital cardiac disease & 3 & 6 & \\
\hline Diabetes & 3 & 1 & \\
\hline Obstructive lung disease & 3 & 2 & \\
\hline Statin therapy & 8 & 10 & \\
\hline $\begin{array}{l}\text { ACE inhibitor or receptor } \\
\text { blocker therapy }\end{array}$ & 3 & 4 & \\
\hline \multicolumn{4}{|l|}{ Critical care data } \\
\hline Total Bypass time (mins) $^{\mathrm{H}}$ & $115 \pm 39$ & $117 \pm 35$ & 0.91 \\
\hline Total Cross Clamp time $^{\mathrm{H}}$ & $89 \pm 43$ & $86 \pm 28$ & 0.87 \\
\hline $\begin{array}{l}\text { ICU length of stay, days } \\
\text { (Median) }\end{array}$ & $2.5(1)$ & $2.5(2)$ & $0.62^{\#}$ \\
\hline $\begin{array}{l}\text { Hospital length of stay, days } \\
\text { (Median) }\end{array}$ & $11.2(8)$ & $10.5(9)$ & $0.44^{\#}$ \\
\hline $\begin{array}{l}\text { Mean Blood glucose during } \\
\text { critical care admission } \\
\mathrm{mmol} / \mathrm{l}\end{array}$ & 7.48 & 7.35 & 0.56 \\
\hline $\begin{array}{l}\text { IV Insulin therapy whilst in } \\
\text { critical care (n) }\end{array}$ & 10 & 10 & \\
\hline $\begin{array}{l}\text { Mean insulin dose during } \\
\text { critical care admission, if } \\
\text { treated with IV insulin } \\
\text { (Units/hr) }\end{array}$ & 2.16 & 1.91 & 0.46 \\
\hline Exposure to NMBs (n) & 0 & 0 & \\
\hline $\begin{array}{l}\text { Exposure to corticosteroids } \\
\text { (n) }\end{array}$ & 3 & 4 & \\
\hline
\end{tabular}

Table 1: Demographic data, co-morbidities and critical care data for Non-wasting $(n=19)$ and wasting patients. Data presented as mean \pm SD unless otherwise stated. * Weight unavailable for 2 patients in the wasting group therefore $n=21$, tPre operative EF not available for 1 patient in each group. ${ }^{H} 4$ patients in the non wasting and 2 in the wasting group did not undergo bypass. Pre- op preoperative, LVEF - Left ventricular ejection fraction, NMBs - neuromuscular blocking agents given other than at the time of surgery. 
Supplemental Digital Content

\begin{tabular}{|c|c|c|}
\hline Surgical Procedure & $\begin{array}{l}\text { Non-wasting patients } \\
(n=19)\end{array}$ & $\begin{array}{l}\text { Wasting patients } \\
(\mathrm{n}=23)\end{array}$ \\
\hline CABG & 6 & 3 \\
\hline OPCAB & 1 & 2 \\
\hline \multicolumn{3}{|l|}{ Aortic Valve and Aortic Surgery } \\
\hline AVR & 1 & 4 \\
\hline TAVI & 3 & \\
\hline$A V R$ and $C A B G$ & & 2 \\
\hline $\begin{array}{l}\text { AVR and ascending aorta } \\
\text { replacement }\end{array}$ & 1 & \\
\hline Aortic root and valve repair & & 1 \\
\hline AVR and septal myomectomy & 1 & \\
\hline Aortic arch de-branch & & 1 \\
\hline $\begin{array}{l}\text { Valve sparing aortic root } \\
\text { replacement }\end{array}$ & 1 & \\
\hline \multicolumn{3}{|l|}{ Mitral Valve Surgery } \\
\hline MVR and CABG & 1 & 1 \\
\hline MV repair & 1 & 1 \\
\hline MVR & & 1 \\
\hline MVR and ablation & 1 & \\
\hline $\begin{array}{l}\text { MVR and TV annuloplasty and } \\
\text { CABG }\end{array}$ & & 1 \\
\hline \multicolumn{3}{|l|}{ Congenital Cardiac Surgery } \\
\hline Redo AVR (congenital) & & 1 \\
\hline Redo PVR (congenital) & 1 & 1 \\
\hline $\begin{array}{l}\text { Relief of RVOT obstruction and } \\
\text { PVR }\end{array}$ & 1 & \\
\hline AVR and Ross procedure & & 1 \\
\hline $\begin{array}{l}\text { AVR, PVR and pulmonary trunk } \\
\text { augmentation }\end{array}$ & & 1 \\
\hline TVR and closure of ASD & & 1 \\
\hline ASD closure & & 1 \\
\hline
\end{tabular}

Suppl Table 1: Number of patients undergoing different surgical procedures in the non-wasting and wasting patient groups. (CABG - Coronary artery bypass grafting, OPCAB- Off pump coronary artery bypass, AVR- Aortic Valve replacement, TAVI-transcutaneous aortic valve insertion, MVR - Mitral Valve replacement, PVR - pulmonary valve replacement, RVOT - right ventricular outflow tract, TVR - Tricuspid Valve replacement, ASD- Atrial septal defect.) 


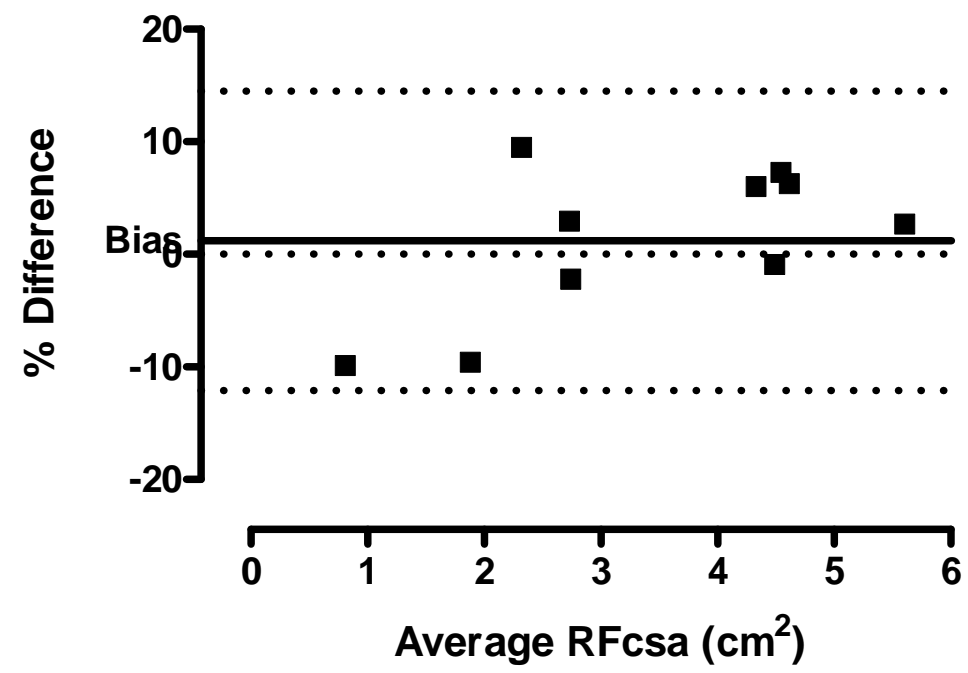

Suppl Fig 1: Bland- Altman Plot to show repeatability Rectus Femoris Ultrasound Cross sectional area (RFcsa) measurements. Dotted lines - limits of agreement (-12.1 to 14.5\%). Significant change in $\mathrm{RFcsa}=9.24 \%$ (1.65 $\times$ Coefficient Variation) . 